\title{
Associations between adipokines gene polymorphisms and knee osteoarthritis: a meta-analysis
}

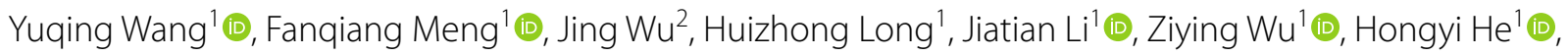

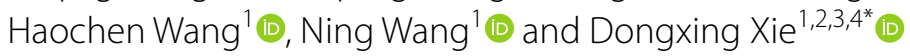

\begin{abstract}
Background: Adipokines gene polymorphisms are speculated to be associated with the risk of knee osteoarthritis $(\mathrm{OA})$, but evidence remains conflicting. This study therefore aimed to examine whether associations exist between adipokines gene polymorphisms and knee OA by considering the evidence collected from eligible studies through a meta-analysis.
\end{abstract}

Methods: A systematic search was performed on PubMed, Embase, Web of Science, China National Knowledge Infrastructure (CNKI), and Wanfang up to March 31, 2020. Meta-analysis was carried out by focusing on the associations between adipokines gene polymorphisms and knee OA with the allele model, dominant model, and recessive model.

Results: The present meta-analysis included 5 eligible studies for ADIPOQ rs 1501299 with 1,021 cases and 1,097 controls, 3 eligible studies for ADIPOQ rs2241766 with 549 cases and 544 controls, 3 eligible studies for LEPR rs 1137101 with 808 cases and 856 controls, 2 eligible studies for VISFATIN rs4730153 with 339 cases and 680 controls and 2 eligible studies for VISFATIN rs 16872158 with 339 cases and 680 controls. Significant association was observed between LEPR rs 1137101 and knee OA in the overall population (recessive: $\mathrm{OR}=0.40,95 \% \mathrm{Cl} 0.21-0.79$ ). Limited data revealed that associations may exist between ADIPOQ rs2241766 and knee OA in Asians (dominant: OR = 1.35, 95\% CI 1.031.78), between VISFATIN rs4730153 and knee $O A$ in Asians (allele: $O R=0.58,95 \% \mathrm{Cl} 0.41-0.83$; dominant: $O R=0.57$, 95\% Cl 0.39-0.83), and between VISFATIN rs 16872158 and knee OA in Asians (allele: $\mathrm{OR}=1.84,95 \% \mathrm{Cl} 1.26-2.68$; dominant: $\mathrm{OR}=1.94,95 \% \mathrm{Cl} 1.31-2.89)$.

Conclusions: Adipokines gene polymorphisms may be associated with knee OA. The association was observed in LEPR rs 1137101 in the present study. In addition, limited data revealed that associations may also exist in ADIPOQ rs2241766, VISFATIN rs4730153 and VISFATIN rs16872158.

Prospero registration: CRD42020187664.

Keywords: Meta-analysis, Adipokines, Knee osteoarthritis, Polymorphisms

*Correspondence: xdx1024@csu.edu.cn

1 Department of Orthopaedics, Xiangya Hospital, Central South University, Changsha, Hunan, China

Full list of author information is available at the end of the article

\section{Background}

Osteoarthritis (OA), a highly prevalent disease, was estimated to affect 250 million people worldwide at present [1], and has therefore become a major contributor to global disability [2]. OA is characterized by degeneration of articular cartilage, synovial inflammation and bone remodeling, which can consequently original author(s) and the source, provide a link to the Creative Commons licence, and indicate if changes were made. The images or other third party material in this article are included in the article's Creative Commons licence, unless indicated otherwise in a credit line to the material. If material is not included in the article's Creative Commons licence and your intended use is not permitted by statutory regulation or exceeds the permitted use, you will need to obtain permission directly from the copyright holder. To view a copy of this licence, visit http://creativecommons.org/licenses/by/4.0/. The Creative Commons Public Domain Dedication waiver (http://creativeco mmons.org/publicdomain/zero/1.0/) applies to the data made available in this article, unless otherwise stated in a credit line to the data. 
lead to pain, physical activity limitations and markedly reduced quality of life [3]. At present, pharmacological treatment options for OA lack approved disease-modifying therapies and are largely limited to the relief of symptoms [4], for end-stage OA patients, joint replacement is demanded [5]. Elucidation of the underlying etiology of OA would be helpful for confirming diagnosis in early stages, therefore facilitating timely and effective clinical decision making. OA has a multifactorial pathophysiology, which may involve mechanical, metabolic and inflammatory contributors [6]. In addition, genetic factors may explain a large part of the susceptibility to OA [7]. In the past few years, several studies reported OA risk loci have been published [8-12], including genome-wide association studies which discovered DNA variants, primarily the single nucleotide polymorphisms (SNPs) in large cohorts [12]. Insights from these relevant studies have firmly placed OA into the polygenic category of common diseases [13-16].

The recognized prominent risk factors of $\mathrm{OA}$ include increasing age, female sex and obesity [4]. In particular, obesity is a well-established risk factor [4] due to its potential contribution in the mechanical aspect by increasing the joint load [17], as well as in the metabolic aspect by playing the role of adipose tissue as an endocrine organ secreting a variety of metabolicallyactive mediators. Among these secreted mediators, adipokines are a main type [17]. Indeed, adipose tissue has been confirmed to release an array of adipokines including adiponectin, leptin, resistin, and visfatin $[17$, 18], among which leptin was first discovered by Friedman et al. in 1994 [19]. Then, in 2003, Dumond et al. [20] derived the earliest evidence supporting a pivotal role of leptin in OA. This milestone study initiated the journey to examine adipokines as a possible metabolic link between obesity and OA.

Knee is the most common site in OA [1], Several SNPs of the adipokines genes have been associated with knee OA [21-32], but the results are inconsistent. For instance, a study from Thailand rejected any significant association between the ADIPOQ gene rs1501299 polymorphism and knee OA [24], while Jin et al. reported that rs1501299 polymorphism intensified the risk of knee OA in Chinese subjects.

[21]. In view of the limitations in deriving comprehensive conclusions from individual studies and the inconsistency among different studies, we intended to conduct a meta-analysis to clarify whether the main types of adipokines gene SNPs could be associated with the susceptibility to knee OA.

\section{Methods}

\section{Search methods}

The PubMed, Embase, Web of Science, China National Knowledge Infrastructure (CNKI), and Wanfang databases were searched through to retrieve observational studies that focused on the associations between adipokines gene polymorphisms and OA up to March 31, 2020 (Appendix). The present meta-analysis has been conducted according to the Preferred Reporting Items for Systematic Reviews and Meta-analyses (PRISMA) reporting guideline (Additional file 1).

\section{Inclusion and exclusion criteria}

Two investigators assessed the retrieved studies independently according to the pre-specified inclusion criteria as follows: (1) knee OA was diagnosed based on the American College of Rheumatology criteria or radiographic findings, or the patient received total joint replacement because of primary knee OA; (2) observational studies that investigated the associations between adipokines gene polymorphisms and knee $\mathrm{OA}$; (3) observational studies that compared knee OA patients with healthy controls; (4) the allele and genotype distributions of healthy controls were compliant with the Hardy-Weinberg equilibrium (HWE) model; (5) the frequency distributions of alleles and genotype were available. The exclusion rules were: (1) duplicated publications; (2) conference abstracts or commentaries; (3) animal or in vitro studies; (4) review articles.

\section{Data extraction and evaluation of study quality}

Two investigators extracted the desired data (i.e., authors, publication year, study design, country, OA site, genotype method, sample size of the case group and control group, and the allele and genotype frequency of adipokines SNPs) from eligible studies independently.

Another two investigators analyzed the methodological quality of each study independently by applying the Newcastle-Ottawa Scale (NOS) [33], in terms of the selection of study participants, comparability of outcome groups and outcome measures. A NOS score $>6$ indicated a high-quality study $[34,35]$.

\section{Statistical analysis}

The conformity of the distributions of observed allele or genotype frequencies to HWE in the control group was verified by chi-square test. The statistical heterogeneity was tested by $I^{2}$ statistics. The odd ratios (ORs) and $95 \%$ confidence intervals (CIs) were estimated by the random effects model in case of high heterogeneity $\left(I^{2}>50 \%\right)$, and by the fixed effects model in case of 
low heterogeneity [36]. Publication bias was examined by the Begg's test [37] and the Egger's test [38], where $P<0.05$ implied statistical significance. All data analyses were performed in Stata 15.0 (Stata Corp, College Station, TX, USA).

The meta-analysis was carried out on (1) the allele model, (2) the dominant model, and (3) the recessive model. In order to examine the effects on specific demographic regions, subgroup analyses were performed on each of the different populations. Then, sensitivity analyses were performed to evaluate the impact of any single study on the overall effects by examining the ORs alongside their matching 95\% CIs before and after eliminating each study from the meta-analysis.

\section{Results}

\section{Eligible studies}

Figure 1 shows the flow chart illustrating the selection process. Our meta-analysis included 5 eligible studies for
ADIPOQ rs1501299 (1,021 cases and 1,097 controls), 3 eligible studies for ADIPOQ rs2241766 (549 cases and 544 controls), 3 eligible studies for LEPR rs1137101 (808 cases and 856 controls), 2 eligible studies for VISFATIN rs4730153 (339 cases and 680 controls) and 2 eligible studies for VISFATIN rs16872158 (339 cases and 680 controls) [21-32]. Tables 1 and 2 summarize the main characteristics of the studies included. The allele and genotype distributions of the control group showed consistency with the HWE. All the included studies were judged as high quality (NOS score $>6$ ).

\section{Meta-analysis results}

The included studies covered a total of 14 SNPs from 5 genes, among which 5 SNPs from 3 genes were reported by at least 2 studies and were included into the metaanalysis (see Table 3 and Figs. 2, 3, 4, 5 and 6 for the main meta-analysis results). The pooled ORs and $95 \%$ CIs were

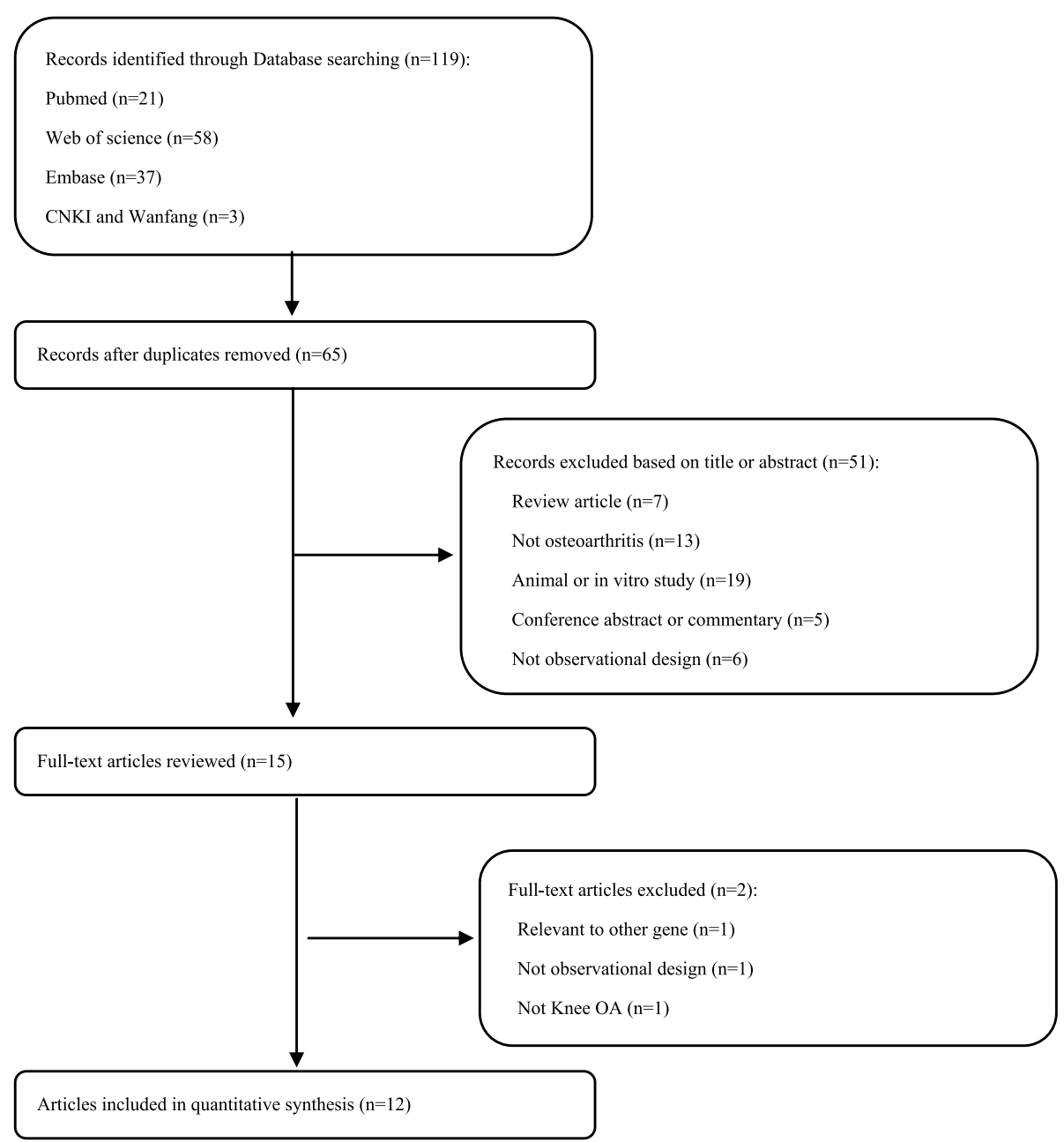

Fig. 1 Selection process of eligible studies 


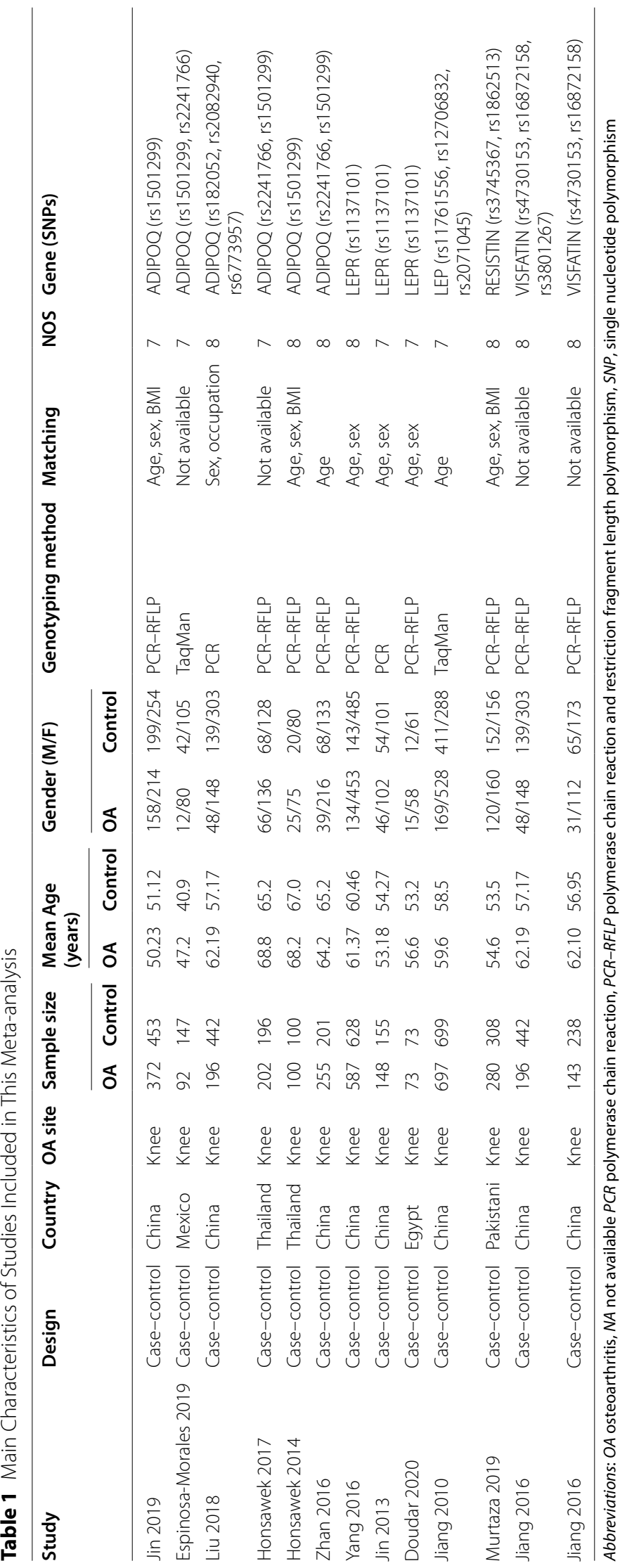


Table 2 Distribution of genotypes among cases and controls

\begin{tabular}{|c|c|c|c|c|c|c|c|}
\hline & \multirow[t]{2}{*}{ Study ID } & \multicolumn{3}{|c|}{ Case group } & \multicolumn{3}{|c|}{ Control group } \\
\hline & & GG & GT & TT & GG & GT & TT \\
\hline \multirow{5}{*}{$\begin{array}{l}\text { ADIPOQ } \\
\text { rs1501299 } \\
(G>T)\end{array}$} & $\operatorname{Jin} 2019$ & 174 & 160 & 37 & 240 & 182 & 30 \\
\hline & Espinosa Morales 2019 & 55 & 29 & 3 & 61 & 40 & 6 \\
\hline & Honsawek 2017 & 106 & 76 & 20 & 102 & 77 & 17 \\
\hline & Honsawek 2017 & 58 & 35 & 7 & 59 & 36 & 5 \\
\hline & Zhan 2016 & 130 & 101 & 24 & 103 & 81 & 17 \\
\hline \multirow{4}{*}{$\begin{array}{l}\text { ADIPOQ } \\
r s 2241766 \\
(T>G)\end{array}$} & & TT & GT & GG & TT & GT & GG \\
\hline & Espinosa-Morales 2019 & 56 & 28 & 3 & 59 & 42 & 3 \\
\hline & Honsawek 2017 & 84 & 93 & 25 & 96 & 75 & 25 \\
\hline & Zhan 2016 & 105 & 120 & 30 & 98 & 78 & 25 \\
\hline \multirow{4}{*}{$\begin{array}{l}\text { LEPR } \\
\text { rs1137101 } \\
(G>A)\end{array}$} & & GG & GA & AA & GG & GA & $A A$ \\
\hline & Yang 2016 & 267 & 271 & 49 & 258 & 291 & 79 \\
\hline & Jin 2013 & 38 & 79 & 31 & 21 & 58 & 76 \\
\hline & Doudar 2020 & 36 & 34 & 3 & 36 & 28 & 9 \\
\hline \multirow{3}{*}{$\begin{array}{l}\text { VISFATIN } \\
\text { rs4730153 } \\
(G>A)\end{array}$} & & GG & $\mathrm{GA}$ & $A A$ & GG & $\mathrm{GA}$ & AA \\
\hline & Jiang 2015 & 170 & 25 & 0 & 350 & 85 & 4 \\
\hline & Jiang 2015 & 124 & 16 & 1 & 189 & 43 & 3 \\
\hline \multirow{3}{*}{$\begin{array}{l}\text { VISFATIN } \\
\text { rs16872158 } \\
(T>A)\end{array}$} & & TT & TA & AA & $\mathrm{TT}$ & TA & AA \\
\hline & Jiang 2015 & 164 & 30 & 1 & 400 & 39 & 2 \\
\hline & Jiang 2015 & 119 & 21 & 1 & 217 & 18 & 1 \\
\hline
\end{tabular}

calculated for the allele model, dominant model, and recessive model respectively.

\section{Association between ADIPOQ rs1501299 polymorphism and knee $O A$}

The included studies focusing on rs1501299 showed no significant heterogeneity in both the overall analysis and subgroup analyses leveled by population groups in all the models. Therefore, all the models were analyzed by the fixed effects model. None of the models showed any significant association in the overall analysis (allele model: $\mathrm{OR}=1.10,95 \% \mathrm{CI} 0.96-1.26, P=0.184$; recessive model: $\mathrm{OR}=1.27,95 \%$ CI $0.92-1.75, P=0.142$; dominant model: $\mathrm{OR}=1.08,95 \%$ CI $0.91-1.29, P=0.376$ ) (Fig. 2). Meanwhile, none of the models showed any significant association in subgroup analyses leveled by population groups either.

\section{Association between ADIPOQ rs2241766 polymorphism and knee $O A$}

The included studies focusing on rs2241766 showed no significant heterogeneity in both the overall analysis and subgroup analyses leveled by population groups in all the models. Therefore, all the models were analyzed by the fixed effects model. None of the models showed any significant association in the overall analysis (allele model: $\mathrm{OR}=1.11,95 \% \mathrm{CI} 0.92-1.34, P=0.279$; recessive model:
$\mathrm{OR}=0.97,95 \%$ CI 0.65 -1.44, $P=0.861$; dominant model: $\mathrm{OR}=1.21,95 \%$ CI $0.95-1.55, P=0.125$ ) (Fig. 3). In subgroup analyses, the rs2241766 polymorphism showed no significant association with knee OA in Europeans and Latin Americans, while statistically significant associations were observed in Asians in the dominant model $(\mathrm{OR}=1.35,95 \% \mathrm{CI} 1.03-1.78, P=0.028)$ (Fig. 3 ).

\section{Association between LEPR rs1137101 polymorphism and knee $O A$}

All models were analyzed by the random effects model in both the overall analysis and subgroup analyses leveled by population groups, due to the existence of significant heterogeneity of rs1137101.

In the overall analysis, significant associations were observed in the recessive model $(\mathrm{OR}=0.40,95 \% \mathrm{CI}$ $0.21-0.79, P=0.008$ ) (Fig. 4). In subgroup analyses, the rs1137101 polymorphism showed no significant association with knee OA in Europeans and Africans, while statistically significant associations were observed in Asians in the recessive model $(\mathrm{OR}=0.43,95 \%$ CI $0.19-0.96$, $P=0.040)$ (Fig. 4).

\section{Association between VISFATIN rs4730153 polymorphism and knee $\mathrm{OA}$}

There is a two-stage study that examined the relationship between rs 4730153 polymorphism and knee OA risk 
Table 3 Meta-analysis of associations between adipokines polymorphisms and OA

\begin{tabular}{|c|c|c|c|c|c|c|c|c|c|c|}
\hline \multirow[t]{2}{*}{ Polymorphism } & \multirow[t]{2}{*}{ Population } & \multirow{2}{*}{$\begin{array}{l}\text { No. of } \\
\text { studies }\end{array}$} & \multicolumn{3}{|c|}{ Tests of association } & \multicolumn{3}{|c|}{ Tests of heterogeneity } & \multirow{2}{*}{$\begin{array}{l}\text { Begg's test } \\
P \text {-value }\end{array}$} & \multirow{2}{*}{$\begin{array}{l}\text { Egger's test } \\
P \text {-value }\end{array}$} \\
\hline & & & OR & $95 \% \mathrm{Cl}$ & $P$-value & Model & $P$-value & $I^{2}(\%)$ & & \\
\hline \multirow{3}{*}{$\begin{array}{l}\text { ADIPOQ } \\
\text { rs1501299 } \\
\text { allele }\end{array}$} & Overall & 5 & 1.10 & $0.96,1.26$ & 0.184 & $\mathrm{~F}$ & 0.426 & 0 & 0.221 & 0.198 \\
\hline & Latin American & 1 & 0.78 & $0.48,1.27$ & 0.326 & / & / & / & l & / \\
\hline & Asian & 4 & 1.13 & $0.98,1.30$ & 0.093 & $\mathrm{~F}$ & 0.604 & 0 & / & / \\
\hline \multirow[t]{3}{*}{ recessive } & Overall & 5 & 1.27 & $0.92,1.75$ & 0.142 & F & 0.744 & 0 & 0.462 & 0.209 \\
\hline & Latin American & 1 & 0.60 & $0.15,2.48$ & 0.481 & / & / & / & / & / \\
\hline & Asian & 4 & 1.33 & $0.95,1.84$ & 0.093 & F & 0.846 & 0 & / & / \\
\hline \multirow[t]{3}{*}{ dominant } & Overall & 5 & 1.08 & $0.91,1.29$ & 0.376 & F & 0.535 & 0 & 0.221 & 0.077 \\
\hline & Latin American & 1 & 0.77 & $0.43,1.38$ & 0.381 & / & / & / & / & / \\
\hline & Asian & 4 & 1.12 & $0.93,1.34$ & 0.228 & F & 0.635 & 0 & / & / \\
\hline \multirow{3}{*}{$\begin{array}{l}\text { ADIPOQ } \\
\text { rs } 2241766 \\
\text { allele }\end{array}$} & Overall & 3 & 1.11 & $0.92,1.34$ & 0.279 & F & 0.403 & 0 & 0.296 & 0.073 \\
\hline & Latin American & 1 & 0.81 & $0.49,1.33$ & 0.402 & / & / & / & / & / \\
\hline & Asian & 2 & 1.17 & $0.96,1.43$ & 0.130 & $F$ & 0.991 & 0 & / & / \\
\hline \multirow[t]{3}{*}{ recessive } & Overall & 3 & 0.97 & $0.65,1.44$ & 0.861 & $F$ & 0.961 & 0 & 0.296 & 0.124 \\
\hline & Latin American & 1 & 1.20 & $0.24,6.11$ & 0.824 & / & / & / & / & / \\
\hline & Asian & 2 & 0.95 & $0.63,1.43$ & 0.813 & F & 0.945 & 0 & / & / \\
\hline \multirow[t]{3}{*}{ dominant } & Overall & 3 & 1.21 & $0.95,1.55$ & 0.125 & $\mathrm{~F}$ & 0.166 & 44.3 & 0.296 & 0.078 \\
\hline & Latin American & 1 & 0.73 & $0.40,1.30$ & 0.283 & / & / & / & I & I \\
\hline & Asian & 2 & 1.35 & $1.03,1.78$ & 0.028 & $\mathrm{~F}$ & 0.977 & 0 & / & / \\
\hline \multirow{3}{*}{$\begin{array}{l}\text { LEPR } \\
\text { rs1137101 } \\
\text { allele }\end{array}$} & Overall & 3 & 0.66 & $0.42,1.03$ & 0.069 & $\mathrm{R}$ & 0.003 & 83.1 & 1.000 & 0.677 \\
\hline & Asian & 2 & 0.61 & $0.32,1.14$ & 0.120 & R & 0.001 & 91.4 & / & / \\
\hline & African & 1 & 0.82 & $0.50,1.36$ & 0.441 & / & I & / & / & I \\
\hline \multirow[t]{3}{*}{ recessive } & Overall & 3 & 0.40 & $0.21,0.79$ & 0.008 & R & 0.029 & 71.7 & 1.000 & 0.661 \\
\hline & Asian & 2 & 0.43 & $0.19,0.96$ & 0.040 & R & 0.010 & 85.1 & / & / \\
\hline & African & 1 & 0.30 & $0.08,1.18$ & 0.084 & / & I & / & / & / \\
\hline \multirow[t]{3}{*}{ dominant } & Overall & 3 & 0.74 & $0.50,1.10$ & 0.137 & R & 0.126 & 51.7 & 1.000 & 0.724 \\
\hline & Asian & 2 & 0.66 & $0.37,1.18$ & 0.158 & R & 0.058 & 72.2 & / & / \\
\hline & African & 1 & 1.00 & $0.52,1.91$ & 1.000 & / & / & / & / & / \\
\hline $\begin{array}{l}\text { VISFATIN } \\
\text { rs } 4730153 \\
\text { allele }\end{array}$ & Asian & 2 & 0.58 & $0.41,0.83$ & 0.003 & $\mathrm{~F}$ & 0.972 & 0 & / & / \\
\hline recessive & Asian & 2 & 0.38 & $0.07,2.26$ & 0.289 & $\mathrm{~F}$ & 0.667 & 0 & / & / \\
\hline dominant & Asian & 2 & 0.57 & $0.39,0.83$ & 0.004 & $\mathrm{~F}$ & 0.946 & 0 & I & / \\
\hline $\begin{array}{l}\text { VISFATIN } \\
\text { rs } 16872158 \\
\text { allele }\end{array}$ & Asian & 2 & 1.84 & $1.26,2.68$ & 0.001 & $F$ & 0.724 & 0 & / & / \\
\hline recessive & Asian & 2 & 1.34 & $0.22,8.14$ & 0.752 & $\mathrm{~F}$ & 0.833 & 0 & / & I \\
\hline dominant & Asian & 2 & 1.94 & $1.31,2.89$ & 0.001 & $\mathrm{~F}$ & 0.747 & 0 & / & / \\
\hline
\end{tabular}

Abbreviations: $R$ random effects model, $F$ fixed effects model

in Asians. The included studies focusing on rs4730153 showed no significant heterogeneity in all the analyses. Therefore, all the models were analyzed by the fixed effects model.

Significant associations were observed in the allele model (OR $=0.58,95 \%$ CI $0.41-0.83, P=0.003)$ and dominant model $(\mathrm{OR}=0.57,95 \%$ CI $0.39-0.83, P=0.004)$ (Fig. 5).
Association between VASFATIN rs16872158 polymorphism and knee $O A$

There is one study containing 2 stages that illustrated the relationship between rs16872158 polymorphism and knee OA risk in Asians. The included studies focusing on rs16872158 showed no significant heterogeneity in all the analyses. Therefore, all the models were analyzed by the fixed effects model. 


\section{a}

Study

$\%$

ID

OR $(95 \%$ Cl) Weight

Asian

Jin (2019)

Honsawek (2017)

Honsawek (2014)

Zhan (2016)

Subtotal (1-squared $=0.0 \%, p=0.604)$

Latin American

Espinosa Morales (2019)

Subtotal (l-squared $=. \%, p=$.)

Overall (1-squared $=0.0 \%, P=0.426$ )

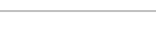

$1.26(1.02,1.56) \quad 38.04$

$1.02(0.75,1.39) \quad 20.45$

$1.09(0.69,1.72) \quad 8.84$

$1.03(0.77,1.37) \quad 23.18$

$1.13(0.98,1.30) \quad 90.51$

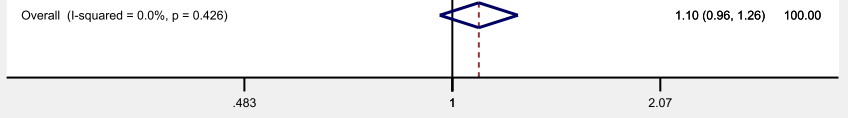

b

study

$0.78(0.48,1.27) \quad 9.49$

$0.78(0.48,1.27) \quad 9.49$

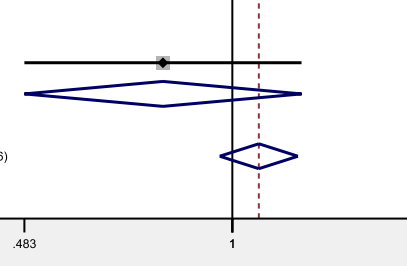

$1.10(0.96,1.26) \quad 100.00$

ID

OR $(95 \%$ Cl) Weight

\section{Asian}

Jin (2019)

Honsawek (2017)

Honsawek (2014)

Zhan (2016)

Subtotal (l-squared $=0.0 \%, \mathrm{p}=0.635)$

Latin American

Latin American
Espinosa Morales (2019)

Subtotal (1-squared $=\%, \mathrm{p}=$.)

Overall (1-squared $=0.0 \%, p=0.535$ )

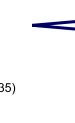

-

$\underset{.432}{1}$

$1.28(0.97,1.69) \quad 36.52$

$0.98(0.66,1.46) \quad 20.40$

$1.04(0.59,1.83) \quad 9.69$

$1.01(0.70,1.46) \quad 22.76$

$1.12(0.93,1.34) \quad 89.37$

$0.77(0.43,1.38) \quad 10.63$

$0.77(0.43,1.38) \quad 10.63$

$1.08(0.91,1.29) \quad 100.00$

C study

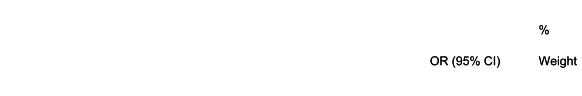

ID

OR (95\% Cl) Weight

$$
\text { Asian }
$$

Jin (2019)

Honsawek (2017)

Honsawek (2014)

Zhan (2016)

Subtotal (1-squared $=0.0 \%, p=0.846)$

Latin American

Espinosa Morales (2019)

Subtotal (1-squared $=. \%, \mathrm{p}=$.)

Overall (I-squared $=0.0 \%, p=0.744$ )
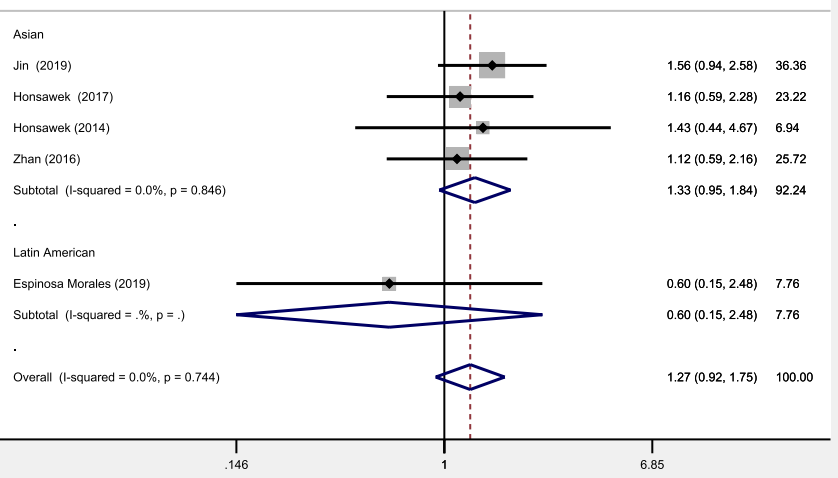

Fig. 2 The associations of ADIPOQ rs1501299 with OA in different genetic models. a allele model. b dominant model. c recessive model 
a

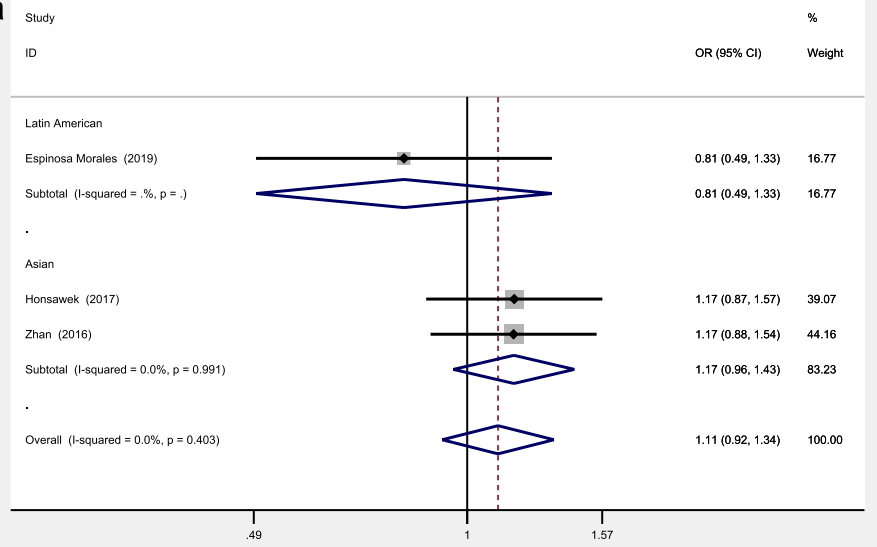

b

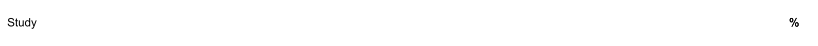

10

OR (95\% Cl) Weight

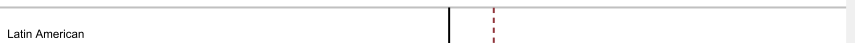

Espinosa Morales (2019)

$0.73(0.40,1.30) \quad 22.74$

Subtotal (1-squared $=\%, p=$.)

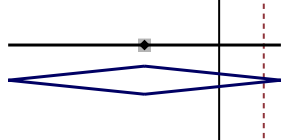

$0.73(0.40,1.30) \quad 22.74$

Asian

Honsawek (2017)

Zhan (2016)

Subtotal (1--squared $=0.0 \%, p=0.977)$

Overall (1-squared $=44.3 \%, \mathrm{p}=0.166)$

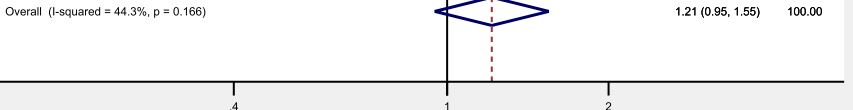

C Study

$1.35(0.91,2.00) \quad 36.38$

$1.36(0.94,1.97) \quad 40.88$

$1.35(1.03,1.78) \quad 77.26$

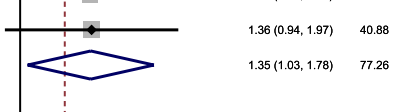

ID

OR $(95 \% \mathrm{Cl}) \quad$ Weight

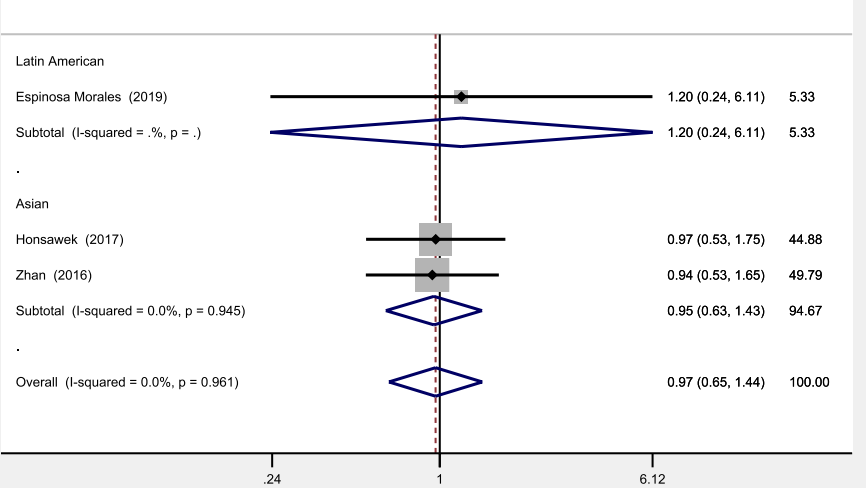

Fig. 3 The associations of ADIPOQ rs2241766 with OA in different genetic models. a allele model. b dominant model. c recessive model 
a

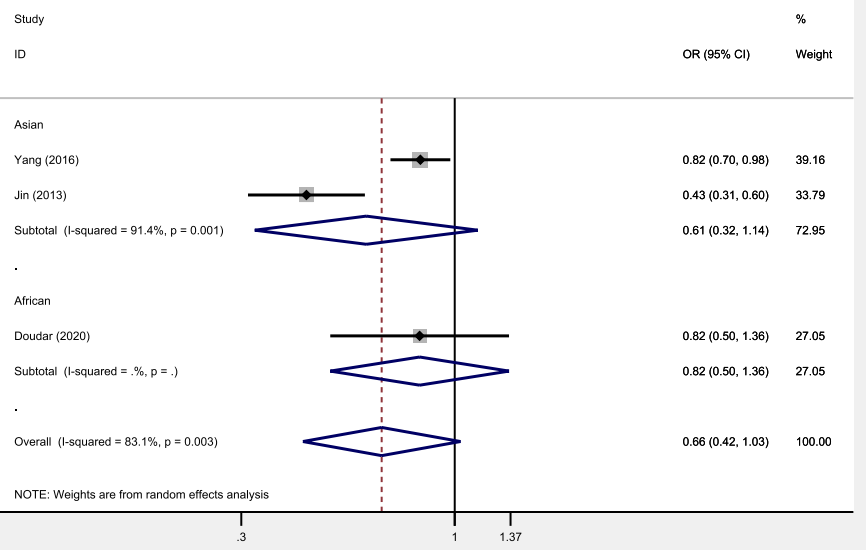

b study

ID

$\mathrm{OR}(95 \% \mathrm{Cl}) \quad$ Weight

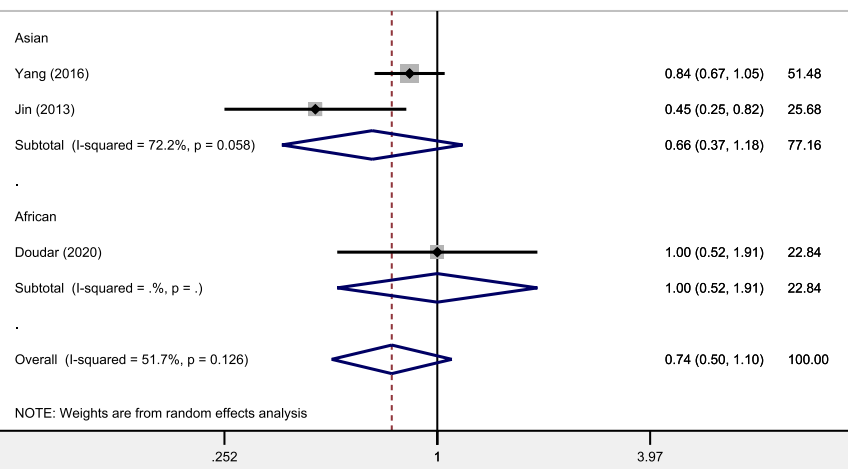

C study

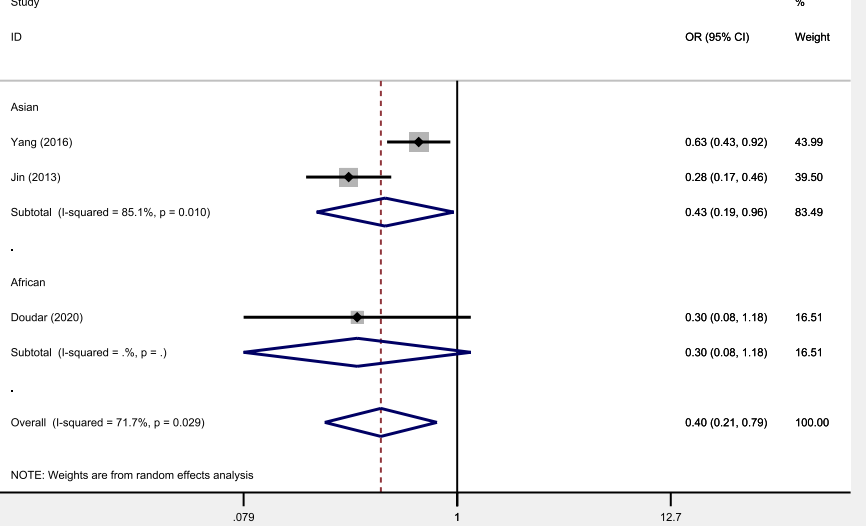

Fig. 4 The associations of LEPR rs1 137101 with OA in different genetic models. a allele model. b dominant model. c recessive model 
a

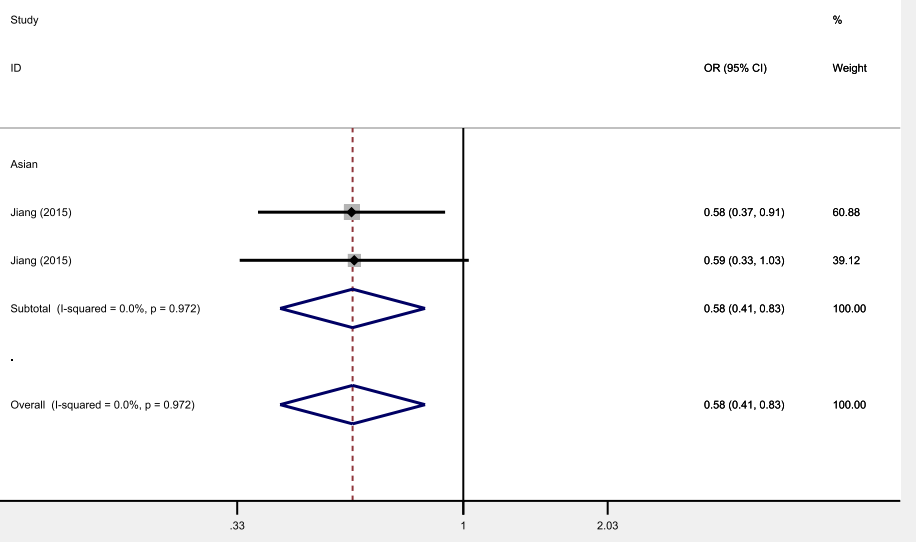

b sudy
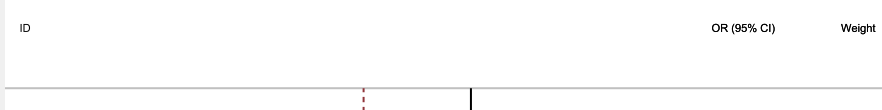

Asian

Jiang (2015)

Jiang (2015)

Subtotal (1-squared $=0.0 \%, p=0.946$ )

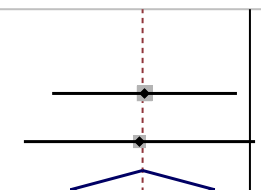

$0.58(0.36,0.93) \quad 61.14$

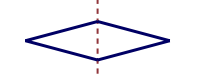

$0.56(0.31,1.03) \quad 38.86$

$0.57(0.39,0.83) \quad 100.00$
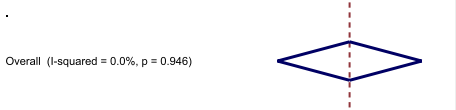

$0.57(0.39,0.83)$

100.00

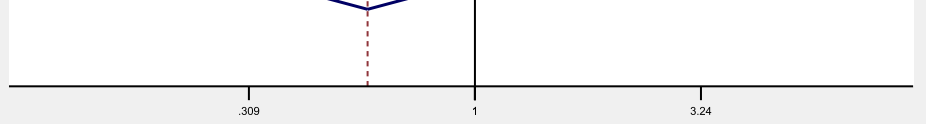

C

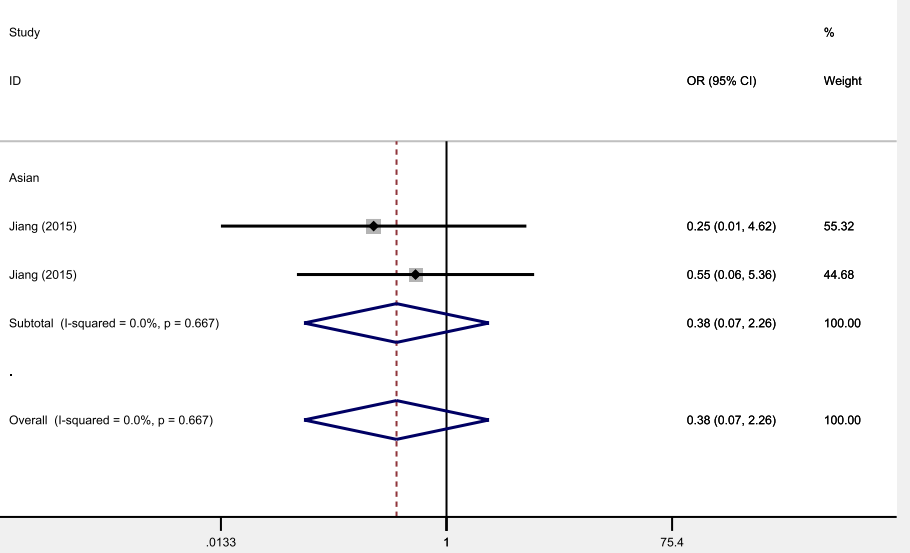

Fig. 5 The associations of VISFATIN rs4730153 with OA in different genetic models. a allele model. b dominant model. c recessive model 
a Study

ID

(1)

Asian

Jiang (2015)

Jiang (2015)

Subtotal (I-squared $=0.0 \%, p=0.724$ )

Overall (I-squared $=0.0 \%, p=0.724$ )

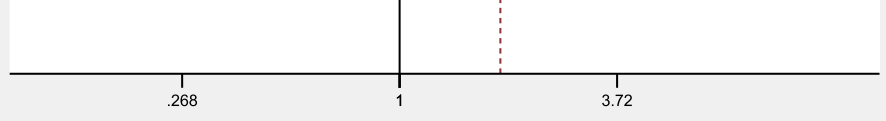

b

study

ID

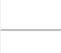

Asian

Jiang (2015)

Jiang (2015)

Subtotal (I-squared $=0.0 \%, p=0.747$ )

Overall (I-squared $=0.0 \%, p=0.747$ )

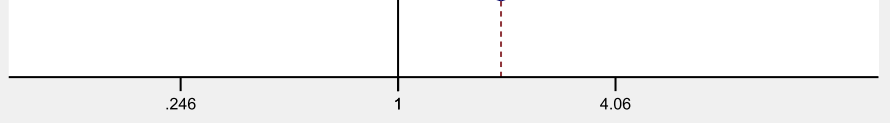

C

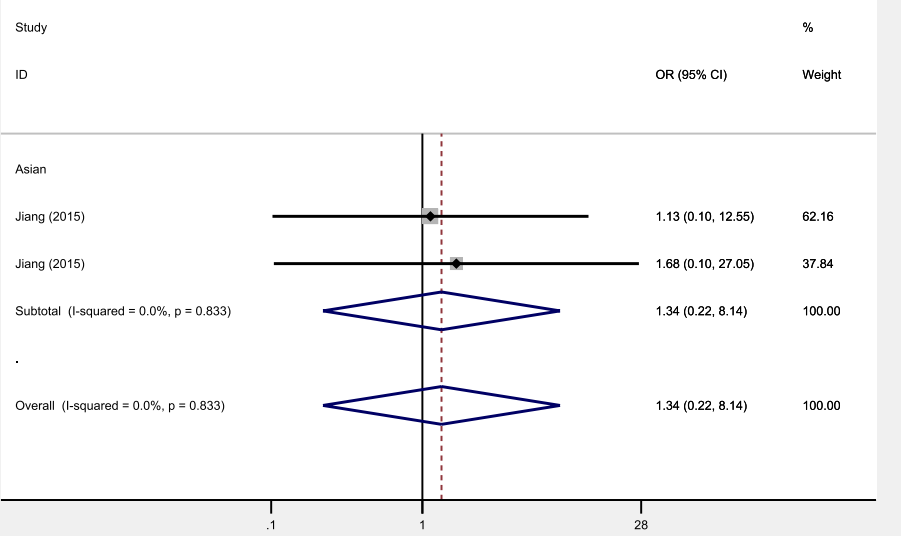

Fig. 6 The associations of VISFATIN rs16872158 with OA in different genetic models. a allele model. b dominant model. c recessive model 
Significant associations were observed in the allele model $(\mathrm{OR}=1.84,95 \% \mathrm{CI} 1.26-2.68, P=0.001)$ and dominant model $(\mathrm{OR}=1.94,95 \% \mathrm{CI} 1.31-2.89, P=0.001)$ (Fig. 6).

Publication bias.

No publication bias was evidenced in the included studies by the Egger's test and Begg's test. Table 3 and Fig. 7 presents the test results of publication bias on each gene polymorphism.

\section{Sensitivity analyses}

In view of the significant heterogeneity in studies on the rs1137101 allele model, recessive model, and dominant model, sensitivity analyses were performed to examine the impact of any single study on the aggregate findings above based on the ORs with the matching 95\% CIs before and after eliminating each study from the metaanalysis. The results remained consistent in all the models of gene polymorphisms above.

\section{Discussion}

The present meta-analysis critically reviewed 5 studies for ADIPOQ rs1501299, 3 studies for ADIPOQ rs2241766, 3 studies for LEPR rs1137101, 2 studies for VISFATIN rs4730153 and 2 studies for VISFATIN rs16872158. Significant association was observed between LEPR rs1137101 and knee OA in the overall population and limited data revealed that associations may exist between ADIPOQ rs2241766 and knee OA in Asians, between VISFATIN rs4730153 and knee OA in Asians, and between VISFATIN rs16872158 and knee OA in Asians.

SNPs can affect OA phenotype through various mechanisms which may include.

post-translational modification of histones, noncoding RNAs, and DNA methylation [39], of which the latter is the most well-studied [40]. Studies of the cartilage DNA methylome have led to the discovery of OAassociated methylation quantitative trait loci (mQTLs), at which there is a correlation between genotype at an OA risk SNP and DNA methylation [13, 41-43]. Several OA risk loci have been identified which colocalise with genes encoding histone-modifying proteins [44-48]. The expression of these histone-modifying proteins is essential for cartilage homeostasis [39]. Meanwhile, OA risk SNPs have been identified in the region of cartilagespecific non coding RNAs that are known to be vital for homeostasis of the articular joint surface and are dysregulated in OA [41, 49].

Studies have been published on the associations of 2 SNPs (rs2241766 and rs1501299) in the ADIPOQ gene with knee OA, but the results were inconsistent. According to a study from Mexico, no association was observed between ADIPOQ rs2241766 and the risk of knee OA, but the effect of the interaction between polymorphisms ADIPOQ rs1501299 and PON1 rs662 seemed to play an important role in the knee OA pathogenesis. Two studies conducted by Honsawek et al. from Thailand found no association between ADIPOQ rs2241766 or rs1501299 polymorphism and the risk of knee OA [24, 25]. However, another two studies focusing on the Chinese population reported significant associations between ADIPOQ rs2241766 and rs1501299 polymorphisms and an increased risk of knee OA [21, 26]. These conflicting findings might be attributed to two reasons. The first one might be the genetic heterogeneity among different ethnicities, The second reason might be the varying sample sizes across different studies, which might introduce differences in data accuracy; moreover, a small sample size might even lead to false-

positive results. In the present meta-analysis, by investigating the associations of 2 SNPs (rs2241766 and rs1501299) with the risk of knee OA, we produced a hint that rs2241766 within the ADIPOQ gene might be a predisposing factor for the risk of knee OA in Asians.

Adiponectin, an adipocyte-derived hormone with multiple biological functions [50, 51], is traditionally considered as an anti-inflammatory adipokine in various disease states, including type 2 diabetes, nonalcoholic fatty liver disease and cardiovascular disease [52-57]. However, the role of adiponectin in the pathogenesis of OA remains controversial. On one hand, adiponectin was found to play a pro-

inflammatory role in OA. Adiponectin can stimulate the expression of interleukin- 6 and matrix metalloproteinase- $1 /-3 /-13$, and the production of inducible nitric oxide synthase in both chondrocytes and OA synovium fluids through the mitogen-activated protein kinases, AdipoR1/5'-AMP-activated protein kinase, and the nuclear factor-

kappa B pathway, which may eventually lead to inflammation and matrix degradation in patients with $\mathrm{OA}$ [58-60]. On the other hand, serum adiponectin levels were found to be negatively associated with knee OA and synovial inflammation in destabilization of the medial meniscus and tibial fracture models [61, 62], indicating that adiponectin may play an anti-inflammatory role in $\mathrm{OA}$. There were evidences supporting the existence of an association between rs2241766 and alterations of plasma adiponectin, especially in the Asian population [63-66]. Rs2241766, the exonic SNP, is a silent polymorphism which would not lead to changes in the sequence of amino acids [67]. However, evidence has been reported that many genes related to human diseases harbor exonic mutations could influence the pre-mRNA splicing [68]. In particular, the translationally silent mutations might inactivate genes by inducing the splicing machinery to 


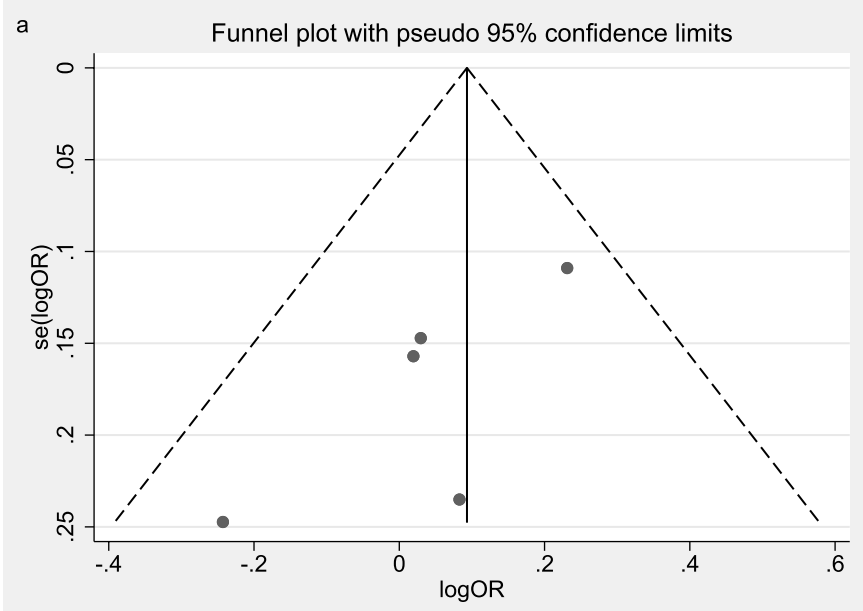

b

Funnel plot with pseudo $95 \%$ confidence limits

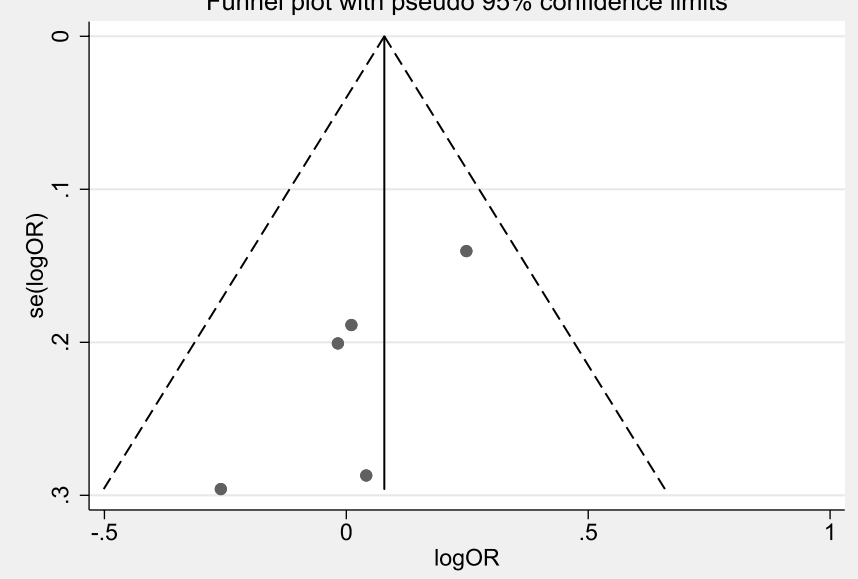

c

Funnel plot with pseudo $95 \%$ confidence limits

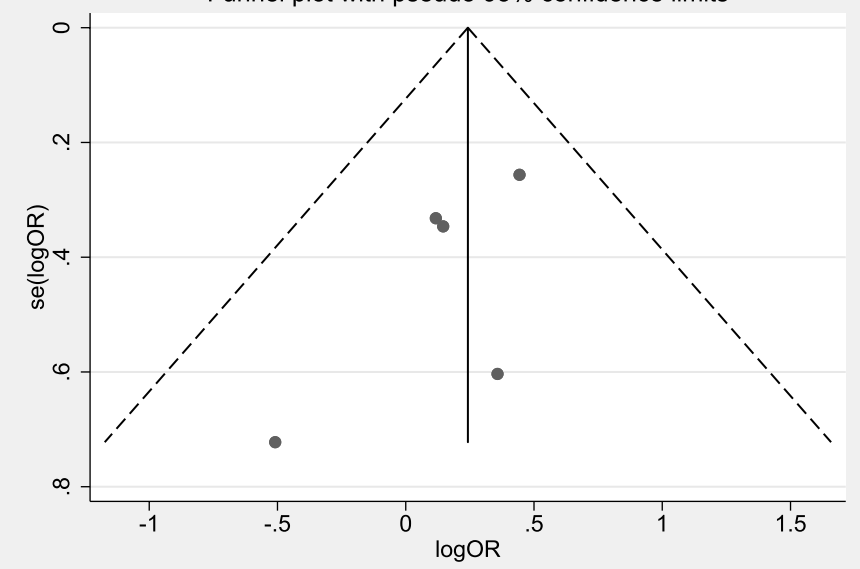

Fig. 7 Funnel plot of publication bias for the association of ADIPOQ (rs1501299) polymorphism with OA in different genetic models. a allele model. b dominant model. c recessive model 
skip mutant exons [68]. Consequently, SNP rs2241766 might affect the plasma level of adiponectin by affecting the splicing efficiency and/or accuracy of adiponectin mRNA [68]. Although the exact mechanism of rs2241766 modulation underlying OA susceptibility is still unclear, the data from the present study may provide a better understanding of its functional relevance to the pathogenesis of OA.

Two studies targeting at the Chinese population indicated an association between LEPR SNP and the susceptibility to knee OA; hence, it was speculated that there might be a genetic marker predicting the risk of this disease $[27,28]$. On the contrary, Doudar et al. reported neither direct genetic association between rs1137101 SNP and the susceptibility of primary knee OA nor any gender difference in the frequency distribution of alleles or genotypes in Egyptians [30]. In the present meta-analysis, rs1137101 within the LEPR gene was found to be associated with a reduced risk of knee OA in the overall population and the Asian subgroup. Recently, due to the pro- inflammatory and pro-catabolic activities on the cartilage, the impaired leptin signal transduction was recognized as a new factor in the pathophysiology of OA [69]. Furthermore, due to the regulatory role of LEPR SNPs in the leptin signal pathway and the expression of LEPR in the cartilage [70, 71], LEPR was speculated to be a genetic risk factor for OA. By using arginine at codon 223 to replace the amino acid glutamine, the SNP rs1137101 in the LEPR gene represented a change in the extracellular domain of the LEPR protein, which would consequently result in structural changes in LEPR and potential alterations of the signaling capacity of leptin [72].

Visfatin is a multi-faceted, ubiquitous protein that acts on a number of diseases including OA [73, 74]. In accordance with a two-stage case-control study by Jiang et al. that examined the associations between 3 tagging polymorphisms in the VISFATIN gene and the risk of knee OA based on a sample containing 339 OA patients and 680 healthy subjects [32], the rs4730153 in VISFATIN appeared to be significantly associated with a reduced risk of knee OA, while the rs16872158 in VISFATIN was associated with an increased risk of knee OA in Chinese subjects. In view of that the genetic factors may be affected by different disease patterns, severities, genders and populations, more large-scale replication studies are needed to further verify the results related to SNPs on different population groups. It has been established that visfatin plays a role in the pro-inflammation process of OA. Meanwhile, 2 important mediators of cartilage destruction (i.e., IL-1 $\beta$ and lipopolysaccharide) in OA could enhance visfatin expression [75], which implied the existence of associations between inflammatory cytokines and visfatin [76]. Consistently, visfatin has been demonstrated to induce the expressions of IL-6 and monocyte chemoattractant protein 1 in chondrocytes and osteoblasts, implying a deleterious effect of this cytokine on OA [77]. Although evidence has been reported about the mechanism of visfatin underlying $\mathrm{OA}$, there is a lack of evidence illustrating the mechanisms of rs4730153 and rs16872158 in affecting the expression of visfatin. In this regard, our study may provide a hint for detecting the pathogenesis of OA from a novel aspect.

Several limitations in this meta-analysis need to be highlighted. Firstly, some of the included studies did not match the confounding factors such as age, sex and BMI between case group and control group, and different factors for matching might increase the probability of residual confounding. Secondly, as the targeted populations were confined to Latin Americans and Asians, it is unclear whether the results could be generalized to other ethnic groups. Thirdly, there are only a small number of studies focusing on VISFATIN gene polymorphisms, and therefore, the statistical power was not strong enough to examine the associations between VISFATIN polymorphisms and OA. Fourthly, studies illustrated the associations between adipokines and OA mainly focus on knee OA, and there were limited data in hand or hip OA. Fifthly, genetic factors alone are unlikely to reliably identify individuals who will develop OA [5], as lifestyle changes (e.g., exercise, weight loss) may play a role in the development of OA [78]. Sixthly, candidate studies included in meta-analysis often lead to false-positive results due to lack of power, therefore, results should be interpreted with caution. Despite aforementioned limitations, our study is the first meta-analysis focusing on the associations between adipokines gene polymorphisms and the risk of knee OA, and may provide new insights into the etiology of knee OA.

\section{Conclusion}

The present meta-analysis examined the potential associations between adipokines gene polymorphisms and knee OA. The association was observed in LEPR 1,137,101. Additionally, limited data revealed that associations may also exist in ADIPOQ rs2241766, VISFATIN rs4730153 and VISFATIN rs16872158. Further studies on different population groups with high quality and large sample size are needed to confirm and deepen our findings.

\section{Funding statement}

This work was supported by the National Natural Science Foundation of China (81772413, 81702206), the National Key Research and Development Program of China (2018YFB1105705), the Xiangya Clinical Big Data System Construction Project of Central South University (45), 
the Central South University's Innovation Key Foundation for Graduate (2018zzts256), and the Natural Science Foundation of Hunan Province (2017JJ3491, 2017JJ3492).

\section{Appendix \\ Search strategies \\ Pubmed:}

1. osteoarthriti*[tiab] or osteoarthriti* $[\mathrm{mh}]$ or osteoarthro"[tiab] or gonarthriti*[tiab] or gonarthro*[tiab] or coxarthriti*[tiab] or coxarthro"[tiab] or osteo?arthritis[tiab]

2. polymorphism[tiab] or SNP*[tiab] or variant*[tiab] or mutation[tiab] or genotype[tiab] or allele[tiab] or haplogroup[tiab] or haplotype[tiab] or "genetic predisposition"[tiab] or "genetic susceptibility"[tiab] or "Polymorphism, Single Nucleotide" [MeSH]

3. ADIPOQ[tiab] or adiponectin[tiab] or " $\mathrm{C} 1 \mathrm{Q}$ and collagen domain containing" [tiab] or ACDC[tiab] or ACRP30[tiab] or ADIPQTL1[tiab] or ADPN[tiab] or APM-1[tiab] or APM1[tiab] or GBP28[tiab]

4. LEP[tiab] or leptin[tiab] or OB[tiab] or OBS[tiab] or LEPD[tiab]

5. LEPR[tiab] or "leptin receptor" [tiab] or OBR[tiab] or OB-R[tiab] or CD295[tiab] or LEP-R[tiab] or LEPRD[tiab]

6. RETN[tiab] or resistin[tiab] or ADSF[tiab] or RSTN[tiab] or XCP1[tiab] or FIZZ3[tiab] or RETN1[tiab]

7. NAMPT[tiab] or "nicotinamide phosphoribo syltransferase"[tiab] or VF[tiab] or PBEF[tiab] or PBEF1[tiab] or VISFATIN[tiab] or 1110035O14Rik[tiab]

8. APLN[tiab] or apelin[tiab] or APEL[tiab] or XNPEP2[tiab]

9. CMKLR1[tiab] or "chemerin chemokine-like receptor 1"[tiab] or DEZ[tiab] or RVER1[tiab] or ChemR23[tiab] or CHEMERINR[tiab]

10. lipocalin-2[tiab] or LCN2[tiab] or p25[tiab] or 24p3[tiab] or MSFI[tiab] or NGAL[tiab]

11. or: $3-10$

12. 1 and 2 and 11

\section{Embase:}

1. (osteoarthriti" or osteoarthro* or gonarthriti* or gonarthro* or gonarthro* or coxarthriti" or coxarthro" or arthros* or arthrot*):ti,ab
2. (polymorphism or SNP* or variant* or mutation or genotype or allele or haplogroup or haplotype or "genetic predisposition" or "genetic susceptibility"):ti,ab or ("Polymorphism, Single Nucleotide" $[\mathrm{MeSH}])$

3. (ADIPOQ or adiponectin or "C1Q and collagen domain containing" or ACDC or ACRP30 or ADIPQTL1 or ADPN or APM-1 or APM1 or GBP28):ti,ab

4. (LEP or leptin or OB or OBS or LEPD):ti,ab

5. (LEPR or "leptin receptor" or OBR or OB-R or CD295 or LEP-R or LEPRD):ti,ab

6. (RETN or resistin or ADSF or RSTN or XCP1 or FIZZ3 or RETN1):ti,ab

7. (NAMPT or "nicotinamide phosphoribosyltransferase" or VF or PBEF or PBEF1 or VISFATIN or 1110035O14Rik):ti,ab

8. (APLN or apelin or APEL or XNPEP2):ti,ab

9. (CMKLR1 or "chemerin chemokine-like receptor 1" or DEZ or RVER1 or ChemR23 or CHEMERINR):ti,ab

10. (lipocalin-2 or LCN2 or p25 or $24 \mathrm{p} 3$ or MSFI or NGAL):ti,ab

11. or: $3-10$

12. 1 and 2 and 11

\section{Web of Science:}

1. TOPIC:(osteoarthriti* or osteoarthro* or gonarthriti* or gonarthro* or gonarthro* or coxarthriti" or coxarthro* or arthros" or arthrot*)

2. TOPIC:(polymorphismor SNP* or variant* or mutation or genotype or allele or haplogroup orhaplotype or "genetic predisposition" or "genetic susceptibility") or("Polymorphism, Single Nucleotide" $[\mathrm{MeSH}])$

3. TOPIC:(ADIPOQ or adiponectin or" $\mathrm{C} 1 \mathrm{Q}$ and collagen domain containing" or ACDC or ACRP30 or ADIPQTL1 or ADPN orAPM-1 or APM1 or GBP28)

4. TOPIC:(LEP or leptin or OB or OBSor LEPD)

5. TOPIC:(LEPR or "leptin receptor" or OBR or OB-R or CD295or LEP-R or LEPRD)

6. TOPIC:(RETN or resistin or ADSF or RSTN or XCP1 orFIZZ3 or RETN1)

7. TOPIC:(NAMPT or "nicotinamidephosphoribosyltransferase" or VF or PBEF or PBEF1 or VISFATIN or 1110035O14Rik)

8. TOPIC:(APLN or apelin or APEL or XNPEP2)

9. TOPIC:(CMKLR1 or "chemerin chemokine-like receptor 1"or DEZ or RVER1 or ChemR23 or CHEMERINR) 


\author{
10. TOPIC:(lipocalin-2 or LCN2 or p25 or $24 \mathrm{p} 3$ or \\ MSFI orNGAL) \\ 11. or: $3-10$ \\ 12. 1 and 2 and 11
}

\begin{abstract}
Abbreviations
OA: Osteoarthritis; SNPs: Single nucleotide polymorphisms; NOS: Newcastle-Ottawa Scale; ORs: Odd ratios; Cls: Confidence intervals; NA: Not available; PCR: Polymerase chain reaction; PCR-RFLP: Polymerase chain reaction and restriction fragment length polymorphism; R: Random effects model; F: Fixed effects model.
\end{abstract}

\section{Supplementary Information}

The online version contains supplementary material available at https://doi. org/10.1186/s12891-022-05111-4.

\section{Additional file 1.}

\section{Acknowledgements}

Not applicable.

\section{Authors' contributions}

W. Yuqing: Conceptualized and designed the study, Acquired and interpreted the data, Drafted the manuscript. M. Fanqiang: Searched the literature, Processed the data. W. Jing: Performed the statistical analyses. L. Huizhong: Searched the literature, Processed the data. L. Jiatian: Evaluated the methodological quality of the included studies. W. Ziying: Evaluated the methodological quality of the included studies. H. Hongyi: Acquired and interpreted the data. W. Haochen: Acquired and interpreted the data. W. Ning: Acquired and interpreted the data. X. Dongxing: Conceptualized, designed, and supervised the study, Interpreted the data, Critically reviewed the manuscript. The author(s) read and approved the final manuscript.

\section{Availability of data and materials}

The data analysed during this study are included in the published articles and its supplementary information files.

\section{Declarations}

\section{Ethics approval and consent to participate}

Not applicable.

\section{Consent for publication \\ Not applicable.}

\section{Competing interests}

None declared.

\section{Author details}

${ }^{1}$ Department of Orthopaedics, Xiangya Hospital, Central South University, Changsha, Hunan, China. ${ }^{2}$ Hunan Key Laboratory of Joint Degeneration and Injury, Xiangya Hospital, Central South University, Changsha, China.

${ }^{3}$ Hunan Engineering Research Center for Osteoarthritis, Changsha, China.

${ }^{4}$ National Clinical Research Center for Geriatric Disorders, Xiangya Hospital,

Central South University, Changsha, China.

Received: 1 August 2021 Accepted: 10 February 2022

Published online: 22 February 2022

\section{References}

1. Hunter DJ, Bierma-Zeinstra S. Osteoarthritis Lancet. 2019;393(10182):1745-59.

2. Bowden JL, Hunter DJ, Deveza LA, Duong V, Dziedzic KS, Allen KD, Chan PK, Eyles JP. Core and adjunctive interventions for osteoarthritis: efficacy and models for implementation. Nat Rev Rheumatol. 2020;16(8):434-47.

3. Reynard LN, Barter MJ. Osteoarthritis year in review 2019: genetics, genomics and epigenetics. Osteoarthritis Cartilage. 2020;28(3):275-84.

4. Martel-Pelletier J, Barr AJ, Cicuttini FM, Conaghan PG, Cooper C, Goldring MB, Goldring SR, Jones G, Teichtahl AJ, Pelletier JP. Osteoarthritis Nat Rev Dis Primers. 2016;2:16072.

5. Glyn-Jones S, Palmer AJ, Agricola R, Price AJ, Vincent TL, Weinans H, Carr AJ. Osteoarthritis Lancet. 2015;386(9991):376-87.

6. Urban H, Little CB. The role of fat and inflammation in the pathogenesis and management of osteoarthritis. Rheumatology (Oxford). 2018;57(suppl_4):iv10-21.

7. Eyre $\mathrm{S}$, Orozco G, Worthington J. The genetics revolution in rheumatology: large scale genomic arrays and genetic mapping. Nat Rev Rheumatol. 2017;13(7):421-32.

8. Zengini E, Hatzikotoulas K, Tachmazidou I, Steinberg J, Hartwig FP, Southam L, Hackinger S, Boer CG, Styrkarsdottir U, Gilly A, et al. Genomewide analyses using UK Biobank data provide insights into the genetic architecture of osteoarthritis. Nat Genet. 2018;50(4):549-58.

9. Styrkarsdottir U, Lund SH, Thorleifsson G, Zink F, Stefansson OA, Sigurdsson JK, Juliusson K, Bjarnadottir K, Sigurbjornsdottir S, Jonsson S, et al. Meta-analysis of Icelandic and UK data sets identifies missense variants in $\mathrm{SMO}, \mathrm{IL} 11, \mathrm{COL} 11 \mathrm{~A} 1$ and 13 more new loci associated with osteoarthritis. Nat Genet. 2018;50(12):1681-7.

10. Tachmazidou I, Hatzikotoulas K, Southam L, Esparza-Gordillo J, Haberland V, Zheng J, Johnson T, Koprulu M, Zengini E, Steinberg J, et al. Identification of new therapeutic targets for osteoarthritis through genome-wide analyses of UK Biobank data. Nat Genet. 2019;51(2):230-6.

11. Styrkarsdottir U, Stefansson OA, Gunnarsdottir K, Thorleifsson G, Lund SH, Stefansdottir L, Juliusson K, Agustsdottir AB, Zink F, Halldorsson GH, et al. GWAS of bone size yields twelve loci that also affect height, BMD, osteoarthritis or fractures. Nat Commun. 2019;10(1):2054.

12. Styrkarsdottir $U$, Helgason $H$, Sigurdsson A, Norddahl GL, Agustsdottir AB, Reynard LN, Villalvilla A, Halldorsson GH, Jonasdottir A, Magnusdottir $A$, et al. Whole-genome sequencing identifies rare genotypes in COMP and $\mathrm{CHADL}$ associated with high risk of hip osteoarthritis. Nat Genet. 2017;49(5):801-5.

13. Rice SJ, Cheung K, Reynard LN, Loughlin J. Discovery and analysis of methylation quantitative trait loci (mQTLs) mapping to novel osteoarthritis genetic risk signals. Osteoarthritis Cartilage. 2019;27(10):1545-56.

14. Sandell $\sqcup$. Etiology of osteoarthritis: genetics and synovial joint development. Nat Rev Rheumatol. 2012:8(2):77-89.

15. Minafra L, Bravatà V, Saporito M, Cammarata FP, Forte Gl, Caldarella S, D'Arienzo M, Gilardi MC, Messa C, Boniforti F. Genetic, clinical and radiographic signs in knee osteoarthritis susceptibility. Arthritis Res Ther. 2014;16(2):R91.

16. Miyamoto Y, Mabuchi A, Shi D, Kubo T, Takatori Y, Saito S, Fujioka M, Sudo A, Uchida A, Yamamoto S, et al. A functional polymorphism in the 5'UTR of GDF5 is associated with susceptibility to osteoarthritis. Nat Genet. 2007;39(4):529-33.

17. Pottie P, Presle N, Terlain B, Netter P, Mainard D, Berenbaum F. Obesity and osteoarthritis: more complex than predicted! Ann Rheum Dis. 2006:65(11):1403-5.

18. Gomez R, Lago F, Gomez-Reino J, Dieguez C, Gualillo O. Adipokines in the skeleton: influence on cartilage function and joint degenerative diseases. J Mol Endocrinol. 2009:43(1):11-8.

19. Zhang Y, Proenca R, Maffei M, Barone M, Leopold L, Friedman JM. Positional cloning of the mouse obese gene and its human homologue. Nature. 1994;372(6505):425-32.

20. Dumond H, Presle N, Terlain B, Mainard D, Loeuille D, Netter P, Pottie P. Evidence for a key role of leptin in osteoarthritis. Arthritis Rheum. 2003:48(11):3118-29.

21. Shang H, Hao Y, Hu W, Hu X, Jin Q. Association between ADIPOQ gene variants and knee osteoarthritis in a Chinese population. Biosci Rep. 2019;39(3):BSR20182104.

22. Fernández-Torres J, Martínez-Nava GA, Zamudio-Cuevas Y, MartínezFlores K, Espinosa-Morales R. Epistasis between ADIPOQ rs1501299 and 
PON1 rs662 polymorphisms is potentially associated with the development of knee osteoarthritis. Mol Biol Rep. 2019;46(2):2049-58.

23. Jiang L, Zhu X, Rong J, Xing B, Wang S, Liu A, Chu M, Huang G. Obesity, osteoarthritis and genetic risk: The rs 182052 polymorphism in the ADI$\mathrm{POQ}$ gene is potentially associated with risk of knee osteoarthritis. Bone Joint Res. 2018;7(7):494-500.

24. Zhan D, Thumtecho S, Tanavalee A, Yuktanandana P, Anomasiri W, Honsawek S. Association of adiponectin gene polymorphisms with knee osteoarthritis. World J Orthop. 2017:8(9):719-25.

25. Zhan D, Yuktanandana P, Anomasiri W, Tanavalee A, Honsawek S. Association of adiponectin $+276 \mathrm{G} / \mathrm{T}$ polymorphism with knee osteoarthritis. Biomed Rep. 2014;2(2):229-32.

26. Xiang $\mathrm{D}$, Tang MD, Chen HB. Observation of $+45 \mathrm{~T} / \mathrm{G}$ and $+276 \mathrm{G} / \mathrm{T}$ single nucleotide polymorphisms of adiponectin gene in patients with knee osteoarthritis. Shan Dong Yi Yao. 2016;56(39):23-6.

27. Yang J, Du H, Lv J, Zhang L. Association of rs 1137101 polymorphism in LEPR and susceptibility to knee osteoarthritis in a Northwest Chinese Han population. BMC Musculoskelet Disord. 2016;17:311.

28. Ma XJ, Guo HH, Hao SW, Sun SX, Yang XC, Yu B, Jin QH. Association of single nucleotide polymorphisms (SNPS) in leptin receptor gene with knee osteoarthritis in the Ningxia Hui population. Yi Chuan. 2013;35(3):359-64.

29. Qin J, Shi D, Dai J, Zhu L, Tsezou A, Jiang Q. Association of the leptin gene with knee osteoarthritis susceptibility in a Han Chinese population: a case-control study. J Hum Genet. 2010;55(10):704-6.

30. Fadda SM, Abdelaleem EA, Mohamed RA, Mansour HMH, Doudar NA. Is leptin receptor gene (GIn223Arg) polymorphism associated with disease susceptibility and severity in patients of primary knee osteoarthritis? Egyptian Rheumatologist. 2020;42(1):35-9.

31. Naqvi SKB, Murtaza I, Javed Q. Role of resistin genetic variations in knee osteoarthritis pathogenesis, a cross sectional study. Mol Biol Rep. 2019:46(3):2657-63.

32. Chu M, Rong J, Wang Y, Zhu L, Xing B, Tao Y, Zhuang X, Zhao Y, Jiang L. Strong association of the polymorphisms in PBEF1 and knee OA risk: a two-stage population-based study in China. Sci Rep. 2016;6:19094.

33. Stang A. Critical evaluation of the Newcastle-Ottawa scale for the assessment of the quality of nonrandomized studies in meta-analyses. Eur J Epidemiol. 2010;25(9):603-5.

34. Zhu ZH, Jin XZ, Zhang W, Chen $M$, Ye DQ, Zhai Y, Dong FL, Shen $C L$, Ding C. Associations between vitamin $D$ receptor gene polymorphisms and osteoarthritis: an updated meta-analysis. Rheumatology (Oxford). 2014;53(6):998-1008.

35. Kantor R, Kim A, Thyssen JP, Silverberg JI. Association of atopic dermatitis with smoking: A systematic review and meta-analysis. J Am Acad Dermatol. 2016;75(6):1119-1125.e1111.

36. Higgins JP, Thompson SG. Quantifying heterogeneity in a meta-analysis. Stat Med. 2002:21(11):1539-58.

37. Begg CB, Mazumdar M. Operating characteristics of a rank correlation test for publication bias. Biometrics. 1994;50(4):1088-101.

38. Egger M, Davey Smith G, Schneider M, Minder C. Bias in meta-analysis detected by a simple, graphical test. BMJ. 1997;315(7109):629-34.

39. Rice SJ, Beier F, Young DA, Loughlin J. Interplay between genetics and epigenetics in osteoarthritis. Nat Rev Rheumatol. 2020;16(5):268-81.

40. Aubourg G, Rice SJ, Bruce-Wootton P, Loughlin J. Genetics of osteoarthritis. Osteoarthritis Cartilage. 2021.

41. Boer CG, Yau MS, Rice SJ, Coutinho de Almeida R, Cheung K, Styrkarsdottir U, Southam L, Broer L, Wilkinson JM, Uitterlinden AG. Genome-wide association of phenotypes based on clustering patterns of hand osteoarthritis identify WNT9A as novel osteoarthritis gene. Ann Rheum Dis. 2020;80(3):367-75.

42. Rice SJ, Tselepi M, Sorial AK, Aubourg G, Shepherd C, Almarza D, Skelton AJ, Pangou I, Deehan D, Reynard LN. Prioritization of PLEC and GRINA as Osteoarthritis Risk Genes Through the Identification and Characterization of Novel Methylation Quantitative Trait Loci. Arthritis Rheum. 2019;71(8):1285-96.

43. Rushton MD, Reynard LN, Young DA, Shepherd C, Aubourg G, Gee F, Darlay R, Deehan D, Cordell HJ, Loughlin J. Methylation quantitative trait locus analysis of osteoarthritis links epigenetics with genetic risk. Hum Mol Genet. 2015;24(25):7432-44.

44. Evangelou E, Valdes AM, Castano-Betancourt MC, Doherty M, Doherty S, Esko T, Ingvarsson T, loannidis JP, Kloppenburg M, Metspalu A. The DOT1L rs12982744 polymorphism is associated with osteoarthritis of the hip with genome-wide statistical significance in males. Ann Rheum Dis. 2013;72(7):1264-5.

45. Evangelou E, Kerkhof HJ, Styrkarsdottir U, Ntzani EE, Bos SD, Esko T, Evans DS, Metrustry S, Panoutsopoulou K, Ramos YF. A meta-analysis of genome-wide association studies identifies novel variants associated with osteoarthritis of the hip. Ann Rheum Dis. 2014;73(12):2130-6.

46. Castaño-Betancourt MC, Evans DS, Ramos YF, Boer CG, Metrustry S, Liu Y, den Hollander W, van Rooij J, Kraus VB, Yau MS. Novel Genetic Variants for Cartilage Thickness and Hip Osteoarthritis. PLoS Genet. 2016;12(10):e1006260.

47. Castaño Betancourt MC, Cailotto F, Kerkhof HJ, Cornelis FM, Doherty SA, Hart DJ, Hofman A, Luyten FP, Maciewicz RA, Mangino M. Genomewide association and functional studies identify the DOT1L gene to be involved in cartilage thickness and hip osteoarthritis. Proc Natl Acad Sci USA. 2012;109(21):8218-23.

48. Zeggini E, Panoutsopoulou K, Southam L, Rayner NW, Day-Williams AG, Lopes MC, Boraska V, Esko T, Evangelou E, Hoffman. Identification of new susceptibility loci for osteoarthritis (arCOGEN): a genome-wide association study. Lancet. 2012;380(9844):815-23.

49. Casalone E, Tachmazidou I, Zengini E, Hatzikotoulas K, Hackinger S, Suveges D, Steinberg J, Rayner NW, Wilkinson JM, Panoutsopoulou K. A novel variant in GLIS3 is associated with osteoarthritis. Ann Rheum Dis. 2018;77(4):620-3.

50. Yamauchi T, Kamon J, Ito Y, Tsuchida A, Yokomizo T, Kita S, Sugiyama T, Miyagishi M, Hara K, Tsunoda M, et al. Cloning of adiponectin receptors that mediate antidiabetic metabolic effects. Nature. 2003:423(6941):762-9.

51. Yamauchi T, Nio Y, Maki T, Kobayashi M, Takazawa T, Iwabu M, OkadaIwabu M, Kawamoto S, Kubota N, Kubota T, et al. Targeted disruption of AdipoR1 and AdipoR2 causes abrogation of adiponectin binding and metabolic actions. Nat Med. 2007;13(3):332-9.

52. Gil-Campos M, Cañete RR, Gil A. Adiponectin, the missing link in insulin resistance and obesity. Clin Nutr. 2004;23(5):963-74.

53. Ouchi N, Kihara S, Funahashi T, Matsuzawa Y, Walsh K. Obesity, adiponectin and vascular inflammatory disease. Curr Opin Lipidol. 2003;14(6):561-6.

54. Pischon T, Girman CJ, Hotamisligil GS, Rifai N, Hu FB, Rimm EB. Plasma adiponectin levels and risk of myocardial infarction in men. JAMA. 2004;291(14):1730-7.

55. Maeda N, Shimomura I, Kishida K, Nishizawa H, Matsuda M, Nagaretani $\mathrm{H}$, Furuyama N, Kondo H, Takahashi M, Arita Y. Diet-induced insulin resistance in mice lacking adiponectin/ACRP30. Nat Med. 2002:8(7):731-7.

56. Ouchi N, Kihara S, Funahashi T, Nakamura T, Nishida M, Kumada M, Okamoto Y, Ohashi K, Nagaretani H, Kishida K. Reciprocal association of C-reactive protein with adiponectin in blood stream and adipose tissue. Circulation. 2003:107(5):671-4.

57. Xu A, Wang Y, Keshaw H, Xu LY, Lam KS, Cooper GJ. The fat-derived hormone adiponectin alleviates alcoholic and nonalcoholic fatty liver diseases in mice. J Clin Invest. 2003;112(1):91-100.

58. Kang EH, Lee YJ, Kim TK, Chang CB, Chung JH, Shin K, Lee EY, Lee EB, Song YW. Adiponectin is a potential catabolic mediator in osteoarthritis cartilage. Arthritis Res Ther. 2010;12(6):R231.

59. Tang CH, Chiu YC, Tan TW, Yang RS, Fu WM. Adiponectin enhances IL-6 production in human synovial fibroblast via an AdipoR1 receptor, AMPK, p38, and NF-kappa B pathway. J Immunol. 2007;179(8):5483-92.

60. Tong KM, Chen CP, Huang KC, Shieh DC, Cheng HC, Tzeng CY, Chen KH, Chiu YC, Tang CH. Adiponectin increases MMP-3 expression in human chondrocytes through AdipoR1 signaling pathway. J Cell Biochem. 2011;112(5):1431-40.

61. Griffin TM, Fermor B, Huebner JL, Kraus VB, Rodriguiz RM, Wetsel WC, Cao L, Setton LA, Guilak F. Diet-induced obesity differentially regulates behavioral, biomechanical, and molecular risk factors for osteoarthritis in mice. Arthritis Res Ther. 2010;12(4):R130.

62. Louer CR, Furman BD, Huebner JL, Kraus VB, Olson SA, Guilak F. Dietinduced obesity significantly increases the severity of posttraumatic arthritis in mice. Arthritis Rheum. 2012;64(10):3220-30.

63. Filippi E, Sentinelli F, Trischitta V, Romeo S, Arca M, Leonetti F, Di Mario U, Baroni MG. Association of the human adiponectin gene and insulin resistance. Eur J Hum Genet. 2004;12(3):199-205.

64. González-Sánchez JL, Zabena CA, Martínez-Larrad MT, Fernández-Pérez C, Pérez-Barba M, Laakso M, Serrano-Ríos M. An SNP in the adiponectin 
gene is associated with decreased serum adiponectin levels and risk for impaired glucose tolerance. Obes Res. 2005;13(5):807-12.

65. Hara K, Boutin P, Mori Y, Tobe K, Dina C, Yasuda K, Yamauchi T, Otabe S, Okada T, Eto K, et al. Genetic variation in the gene encoding adiponectin is associated with an increased risk of type 2 diabetes in the Japanese population. Diabetes. 2002;51(2):536-40.

66. Ramya K, Ayyappa KA, Ghosh S, Mohan V, Radha V. Genetic association of ADIPOQ gene variants with type 2 diabetes, obesity and serum adiponectin levels in south Indian population. Gene. 2013;532(2):253-62.

67. Yang WS, Tsou PL, Lee WJ, Tseng DL, Chen CL, Peng CC, Lee KC, Chen MJ, Huang CJ, Tai TY, et al. Allele-specific differential expression of a common adiponectin gene polymorphism related to obesity. J Mol Med (Berl). 2003;81(7):428-34.

68. Cartegni L, Chew SL, Krainer AR. Listening to silence and understanding nonsense: exonic mutations that affect splicing. Nat Rev Genet. 2002;3(4):285-98.

69. Azamar-Llamas D, Hernández-Molina G, Ramos-Ávalos B, Furuzawa-Carballeda J. Adipokine Contribution to the Pathogenesis of Osteoarthritis. Mediators Inflamm. 2017;2017:5468023.

70. Figenschau Y, Knutsen G, Shahazeydi S, Johansen O, Sveinbjörnsson B. Human articular chondrocytes express functional leptin receptors. Biochem Biophys Res Commun. 2001;287(1):190-7.

71. Scotece M, Mobasheri A. Leptin in osteoarthritis: Focus on articular cartilage and chondrocytes. Life Sci. 2015;140:75-8.

72. Li Y, Geng J, Wang Y, Lu Q, Du Y, Wang W, Li Z. The role of leptin receptor gene polymorphisms in determining the susceptibility and prognosis of NSCLC in Chinese patients. J Cancer Res Clin Oncol. 2012;138(2):311-6.

73. Jieyu H, Chao T, Mengjun L, Shalong W, Xiaomei G, Jianfeng L, Zhihong L. Nampt/Visfatin/PBEF: a functionally multi-faceted protein with a pivotal role in malignant tumors. Curr Pharm Des. 2012;18(37):6123-32.

74. Jacques C, Holzenberger M, Mladenovic Z, Salvat C, Pecchi E, Berenbaum F, Gosset M. Proinflammatory actions of visfatin/nicotinamide phosphoribosyltransferase (Nampt) involve regulation of insulin signaling pathway and Nampt enzymatic activity. J Biol Chem. 2012;287(18):15100-8.

75. Santangelo KS, Nuovo GJ, Bertone AL. In vivo reduction or blockade of interleukin-1 $\beta$ in primary osteoarthritis influences expression of mediators implicated in pathogenesis. Osteoarthritis Cartilage. 2012;20(12):1610-8.

76. Hong EH, Yun HS, Kim J, Um HD, Lee KH, Kang CM, Lee SJ, Chun JS, Hwang SG. Nicotinamide phosphoribosyltransferase is essential for interleukin-1 beta-mediated dedifferentiation of articular chondrocytes via SIRT1 and extracellular signal-regulated kinase (ERK) complex signaling. J Biol Chem. 2011;286(32):28619-31.

77. Laiguillon MC, Houard X, Bougault C, Gosset M, Nourissat G, Sautet A, Jacques $C$, Berenbaum F, Sellam J. Expression and function of visfatin (Nampt), an adipokine-enzyme involved in inflammatory pathways of osteoarthritis. Arthritis Res Ther. 2014;16(1):R38.

78. Fernandes L, Hagen KB, Bijlsma JW, Andreassen O, Christensen P, Conaghan PG, Doherty M, Geenen R, Hammond A, Kjeken I. EULAR recommendations for the non-pharmacological core management of hip and knee osteoarthritis. Ann Rheum Dis. 2013;72(7):1125-35.

\section{Publisher's Note}

Springer Nature remains neutral with regard to jurisdictional claims in published maps and institutional affiliations.

Ready to submit your research? Choose BMC and benefit from:

- fast, convenient online submission

- thorough peer review by experienced researchers in your field

- rapid publication on acceptance

- support for research data, including large and complex data types

- gold Open Access which fosters wider collaboration and increased citations

- maximum visibility for your research: over $100 \mathrm{M}$ website views per year

At BMC, research is always in progress.

Learn more biomedcentral.com/submissions 